\title{
CUIDADORES: SEUS AMORES E SUAS DORES
}

\author{
Aline Gonçalves Machado \\ Instituto de Cardiologia do Rio Grande do Sul, Porto Alegre, Brasil \\ Álvaro Roberto Crespo Merlo \\ UFRGS e Hospital de Clínicas de Porto Alegre, Porto Alegre, Brasil
}

\begin{abstract}
RESUMO: Investigaram-se as implicações do trabalho na saúde psíquica dos auxiliares e técnicos de enfermagem que trabalham em unidades críticas de um hospital cardiológico. O aporte teórico utilizado foi o da Psicodinâmica do Trabalho. Os dados foram obtidos através de entrevistas individuais, sendo analisados de forma qualitativa com base na análise de conteúdo. Evidenciou-se que o trabalho proporciona aos profissionais equilíbrio psíquico, na medida em que eles encontram um espaço de criação e reconhecimento daquilo que fazem. Porém, pode-se mostrar nocivo a este equilíbrio na medida em que o trabalhador também sofre com a dor dos pacientes e com o desgaste físico do trabalho.
\end{abstract}

PALAVRAS-CHAVE: trabalho; sofrimento psíquico; enfermagem; unidade crítica.

\section{NURSING ASSISTANTS: LOVES AND PAINS}

ABSTRACT: This study researched the implication of work in the psychological health of nursing assistants who work in critical units of a cardiology hospital. The theoretical approach was the psychodynamics of work. The information was obtained through individual interviews, and analyzed qualitatively by the content analysis method. The results indicate that work provides psychic balance, as the professionals find a space of creation and recognition of what they do. However it can be harmful to psychic balance as the worker also suffers with the patient's pain and with the physical weariness caused by work.

KEY WORDS: work, psychic suffering, nursing, critical unit.

\section{Introdução}

Busca-se, através deste artigo, investigar a relação entre o trabalho dos auxiliares e técnicos de enfermagem e os processos de saúde e adoecimento psíquico desses trabalhadores, buscando analisar as implicações do trabalho na saúde psíquica dos auxiliares e técnicos de enfermagem. Como objetivos específicos, a pesquisa que originou este artigo buscou identificar as experiências geradoras de prazer e sofrimento psíquico no exercício profissional de enfermagem, verificar como o ambiente e a organização de trabalho podem influenciar na geração de prazer e sofrimento psíquico e, ainda, conhecer sintomas entre os trabalhadores de enfermagem como indicativos de sinal de sofrimento psíquico.

De acordo com Dejours (1999), o trabalho tem efeitos muito poderosos sobre o aparelho psíquico, contribuindo para agravar o sofrimento ou, ao contrário, contribuir para subverter o sofrimento, para transformálo em prazer. Assim, o trabalho pode ser ora patogênico, ora estruturante.

Uma das maiores preocupações de Dejours (1992) se refere à centralidade do trabalho, pois considera necessário o entendimento do que se passa no trabalho para a compreensão do que se passa na sociedade como um todo. Segundo Codo, Sampaio e Hitomi (1994), a vida dos homens não se resume ao trabalho, mas também não pode ser compreendida sem ele.

Beck (2001) destaca a necessidade de se entender as demandas sociais e particulares do homem pelo trabalho, pois este compõe a vida das pessoas desde as sociedades mais primitivas, produzindo a sua hominização, e vem se transformando, ao longo da história, para dar conta e atender às demandas sociais e particulares. $\mathrm{O}$ trabalho está situado na hierarquização social dos valores, segundo Sampaio (1995), remetendo-nos para possibilidades diferentes de consumo, felicidade, hierarquia e morte. Portanto, existe uma onipresença do trabalho humano em todas as expressões da vida social.

Para Heller (1991), o trabalhoé uma atividade básica e genérica do homem, caracterizando-se como o intercâmbio entre a sociedade e a natureza, natureza esta entendida não como realidade contemplativa e dada, mas enquanto construção do homem. Assim, o trabalho deve ser a ação que favorece as trocas entre os seres humanos, o que permite uma relação com a natureza, através de sua manipulação, favorecendo o desenvolvimento humano. 
Como refere Vaz (1995), o trabalho possibilita a subsistência do homem, a transformação de si mesmo, a transformação da natureza e a superação da cotidianidade, não tendo, necessariamente, que produzir a alienação do sujeito.

Para compreender os laços entre trabalho e saúde, é indispensável que se investigue as fontes de sofrimento e de prazer dos trabalhadores, conforme coloca Merlo (1999).

A Psicodinâmica do Trabalho (Dejours, 1992) procura evidenciar as formas de expressão de sofrimento e prazer oriundos da inserção do sujeito no mundo do trabalho. Dejours (1994) propõe uma análise no que diz respeito à necessidade de se situar a relação entre saúde mental e trabalho dentro daquilo que a especifica como relação social. Este autor aponta, ainda, que o eixo de análise deve ser deslocado da loucura para a normalidade, pois a maioria dos trabalhadores, apesar das pressões que enfrentam no trabalho, não descompensam psiquicamente (Dejours, 2001).

Atualmente, menciona Tittoni (2002), a abordagem da saúde mental em conjunto com a problemática da saúde do trabalhador propõe uma redefinição do conceito de saúde mental: o trabalho aparece como fator constitutivo de adoecimento e de saúde mental, em que a saúde passa a ser percebida como um movimento dos trabalhadores em direção a melhores condições para viver e trabalhar, e não como um modelo a ser seguido.

Para Dejours e Abdoucheli (1994) o sofrimento ligado ao trabalho produz uma vivência que se articula entre a saúde e a doença, ou seja, é uma vivência intermediária entre estas duas instâncias. E a normalidade não supõe ausência de sofrimento. A normalidade é o resultado das diversas estratégias utilizadas pelos sujeitos para enfrentarem as situações geradoras de sofrimento, transformando-as em prazer, mantendo a estabilização psíquica e somática. Tal sofrimento é inerente ao mundo do trabalho, isto é, ao encontro de um sujeito, com sua trajetória individual e singular, com uma organização do trabalho.

Identificam-se dois tipos de sofrimento: o sofrimento criativo e o sofrimento patogênico. O sofrimento patogênico acontece quando foram explorados todos os recursos defensivos do trabalhador, quando todas as margens de liberdade na transformação, gestão e aperfeiçoamento da organização do trabalho já foram utilizados, dando início à destruição e ao desequilíbrio psíquico do sujeito e, conseqüentemente, ao aparecimento da doença. Isso acontece quando não há nada além das pressões fixas e rígidas, ocasionando a repetição e a frustração, o medo, ou o sentimento de impotência. Quando o sujeito consegue elaborar soluções originais, que possam favorecer a sua saúde, é o sofrimento criativo. Tem-se como origem de ambos os sofrimentos a organização do trabalho.
Diante das adversidades das situações de trabalho, os trabalhadores podem desenvolver estratégias coletivas defensivas, que podem alterar a percepção que eles têm da realidade geradora de sofrimento. Segundo Dejours e Abdoucheli (1994), as estratégias defensivas são uma convenção do grupo que alivia a tensão, diminuindo o desprazer e, muitas vezes, gerando mais trabalho, pois estas estratégias surgem devido às pressões organizacionais do trabalho, contra as quais são construídas e que, para funcionarem, requerem a participação de todos os membros do coletivo.

As defesas individuais são necessárias para lutar contra a doença mental e aliviar o sofrimento, e podem ter como conseqüência somatizações. Sendo assim, o sofrimento é, antes de tudo, expressado no corpo, engajado no mundo e nas relações com o outro (Dejours, 1999). As condições oferecidas pela organização do trabalho podem possibilitar ao trabalhador uma posição psicológica penosa, entrando em conflito com os valores do trabalho bem feito, o senso de responsabilidade e a ética profissional. Para Dejours (2004, p. 281):

A propósito desta organização do trabalho - dada como fato físico -, propúnhamos acerca das atitudes e das condutas humanas uma análise que se afastava sensivelmente do modelo psicopatológico causal: os homens não eram passivos ante os constrangimentos organizacionais, eram capazes de se proteger dos eventuais efeitos nocivos sobre sua saúde mental, bem como de conjurar a saída "natural" que representava o espectro da doença mental. Sofriam, certamente, mas sua liberdade podia ser exercida na construção de estratégias defensivas individuais (por exemplo, a repressão pulsional nas tarefas repetitivas sob o constrangimento do tempo) ou de estratégias defensivas coletivas (por exemplo, as defesas coletivas dos trabalhadores da construção civil).

Assim, frente ao sofrimento no trabalho, os trabalhadores irão buscar defender-se através de estratégias individuais ou coletivas.

Beck (2001) coloca que o enfrentamento das dificuldades oriundas da organização do trabalho e também do próprio trabalhador pode auxiliá-lo a realizar o seu trabalho com mais prazer, visualizando-o como uma possibilidade de construção e reconstrução de si mesmo.

Por outro lado, quando o rearranjo do trabalho não é possível e a relação do trabalhador com a organização do trabalho é bloqueada, o sofrimento patogênico ocorre, pois a energia não descarregada no exercício do trabalho é acumulada no aparelho psíquico, ocasionando um sentimento de desprazer e tensão.

$\mathrm{O}$ trabalhador experimenta-se e transforma-se através das descobertas, recorrendo à inteligência prática ou astuciosa, a qual é descrita por Dejours (1997) como a inteligência que é mobilizada frente ao real do trabalho, aquilo que emerge por sua resistência ao domínio dos 
saberes e do conhecimento disponível. Esta inteligência é utilizada diante de situações inéditas, do imprevisto e frente a situações móveis, e está vinculada aos processos psíquicos utilizados pelos trabalhadores na construção de burlas nas regras de ofício, que transgridem e subvertem as normas prescritas pela organização do trabalho.

Os requisitos sociais para a utilização da inteligência astuciosa referem-se às regras de ofício, e as burlas necessitam ser validadas no campo social. Através do reconhecimento dos superiores hierárquicos, comprova-se a utilidade do que foi criado para a organização do trabalho. Outros requisitos são a organização real e o prescrito do trabalho, pois deve haver um espaço de liberdade entre a organização prescrita e real do trabalho, onde o trabalhador possa exercitar a inteligência astuciosa. Será no espaço entre o que é prescrito nos manuais ou nas definições dos setores de "métodos e processos" das empresas e o que ocorre na prática, no momento da execução da tarefa (que nunca corresponde exatamente ao que foi prescrito), que poderá haver uma intervenção personalizada, que permitirá ao trabalhador reconhecerse como um indivíduo.

\section{O Trabalho em Hospital}

No ambiente hospitalar, as adversidades são inúmeras: a dor, o sofrimento e a constatação da finitude humana, observada pela doença e pela morte. O profissional da saúde se confronta com outros aspectos, descritos por Silva (1998), que também podem originar sofrimento psíquico, tais como a estrutura hierárquica centralizadora, que acaba impossibilitando a ação criativa, gerando conflito entre o ideal e o possível, a competição entre as especialidades das áreas e a existência de corporativismos e a falta de comunicação entre as equipes e familiares.

Trabalhar com pacientes em unidades críticas, tais como as emergências ou as unidades de tratamento intensivo, envolve a imprevisibilidade, a complexidade, onde se destaca a intensa relação desse trabalhador com as questões relacionadas ao processo de morte, traduzidas por um cotidiano de trabalho permeado por vivências ligadas à dor, sofrimento, impotência, angústia, medo, desesperança, desamparo e perdas de diversos tipos.

Osório (2003) refere que os cuidadores, ou seja, os profissionais da área da saúde, ao fornecerem os cuidados ao paciente, promovem seu o bem-estar físico, psicológico e social, adotam uma postura que vai além de suas competências técnicas de lidar com o sofrimento que acompanha a perda da saúde, exercendo suas atividades na fronteira entre a vida e a morte. Isso cria uma sobrecarga emocional diária, também evidenciada a partir das relações com equipe de trabalho e pelo contexto institucional em que atuam. Conforme Beck (2001), va- lorizar e reconhecer o trabalho desses profissionais se faz necessário, pois é uma forma de encontrar prazer e satisfação com sua obra, realçando suas potencialidades enquanto ser humano.

\section{Metodologia}

Realizou-se uma pesquisa exploratória descritiva, com análise de dados qualitativos. Não se buscou generalizar os resultados, mas compreender a realidade que os auxiliares e técnicos de enfermagem enfrentam e como esta interfere na saúde psíquica desses trabalhadores.

Buscou-se compreender quais as implicações do trabalho na saúde psíquica dos auxiliares e técnicos de enfermagem que trabalham em unidades críticas de um hospital especializado em cardiologia. Essa instituição, que atende pacientes oriundos do Sistema Único de Saúde e, também, de convênios, dispõe de 290 leitos e conta com 1.144 funcionários.

Duas estratégias metodológicas distintas foram utilizadas: a pesquisa documental e a realização de entrevistas.

Com a pesquisa documental, buscou-se conhecer o trabalho prescrito e, para tanto, foram utilizados documentos internos elaborados pela Coordenação de Enfermagem do hospital e a Legislação que regulamenta essa profissão.

A coleta de dados foi realizada nos meses de março, abril e maio de 2005, no setor e no horário de trabalho dos funcionários que aceitaram participar da pesquisa.

Em se tratando de pesquisa que utilizou os dados fornecidos pelos funcionários da instituição, foi garantido a estes o sigilo das informações bem como respeitada a sua vontade de participação ou não nesta, através do Termo de Consentimento Livre e Esclarecido, que foi disponibilizado para leitura, explicação de eventuais dúvidas, sendo, então, assinado. As entrevistas foram gravadas e, posteriormente, transcritas.

Os sujeitos de pesquisa foram os auxiliares e técnicos de enfermagem que atuam na Unidade Pós-Operatória e na Emergência de um hospital cardiológico, considerando que auxiliares e técnicos de enfermagem realizam as mesmas tarefas, totalizando 17 funcionários entrevistados. Realizamos nossa investigação nesses dois setores do hospital porque, através da observação que realizamos inicialmente à instituição, verificamos que são duas áreas onde os trabalhadores de enfermagem têm que realizar suas tarefas sob grande pressão. $\mathrm{O}$ critério de escolha dos entrevistados foi o sorteio.

Para a tarefa de analisar e interpretar os dados obtidos através das entrevistas com os sujeitos desta pesquisa, utilizou-se a técnica de Análise de Conteúdo de Bardin (1977). Assim, os resultados serão apresentados tendo como referência as seguintes categorias: o cuidador 
e sua valorização profissional, prazeres e realizações do ato de cuidar, cuidar da dor, a dor do cuidador e o descuido com o cuidador.

Para incluir as falas dos entrevistados utilizamos nomes fictícios, como forma de preservar o sigilo dos entrevistados.

\section{Resultados Prazeres e realizações do ato de cuidar}

Cuidar exige de quem o faz atenção, desvelo, dedicação, renúncia, solicitude, compromisso. Algumas pessoas escolheram como profissão o cuidar. E não é um cuidado qualquer, é cuidar de quem se encontra fragilizado, enfermo, moribundo, sofrendo, desesperado, cuidar daquele que está doente e pode ficar curado, ou cuidar daquele que está morrendo e vai chegar ao fim de sua trajetória. Trata-se de cuidar como profissão, como meio de sobrevivência, como forma de ganhar o seu sustento financeiro e que demanda enfrentar o medo e o desamparo de quem não sabe o que vai acontecer, se vai ficar curado, se vai ficar com limitações da enfermidade ou a morte.

Uns estão resignados, outros inconformados e rebelam-se com a doença, com a limitação, com a submissão em que se encontram, pois o paciente submete-se ao médico, aos remédios, à enfermeira, aos exames, às agulhas, aos auxiliares e técnicos de enfermagem, à alimentação, ao horário e ao controle. Submetem-se na esperança de continuar vivendo, de curar-se, de voltar a sua vida, a sua rotina.

E diariamente há espectadores que acompanham e interferem nesse processo, o auxiliar e o técnico de enfermagem que cuidam, que orientam, que são ouvintes, confidentes daqueles que se encontram doentes. Para Melissa:

Em muitas pessoas que adoecem, a doença é física, mas muitas vezes tá doente o físico e o emocional e precisa daquele algo mais que é a necessidade de ter alguém do lado, a necessidade de chamar a atenção das pessoas. É a necessidade, as pessoas precisam de atenção. Então elas pensam que se ficar mal, vai para um hospital e as pessoas vão ficar em volta dela querendo saber. Acho que é isso... as pessoas estão carentes.

Diante desse cenário de dor e sofrimento, existe o trabalho do auxiliar e do técnico de enfermagem, acompanhando a fragilidade, o desamparo e a necessidade do paciente, atendendo-o, alimentando-o, medicando-o, cuidando-o. Entendendo o trabalho como sendo uma forma de expressão do sujeito, onde ele pode encontrar prazer e satisfação com sua obra, ou seja, sentir-se satisfeito acompanhando o desfecho de quem está doente. Tendo a possibilidade de aliviar o sofrimento do outro.
Para tornar-se auxiliar ou técnico de enfermagem essas pessoas realizaram um curso profissionalizante, que os habilita para a profissão conforme a Lei no 7.498 (Brasil, 1986). Escolheram trabalhar investindo emoção nesse trabalho, pois além da técnica e do conhecimento que o trabalho exige, o paciente necessita de investimento afetivo, precisa de atenção e de uma palavra de consolo. O cuidar exige a humanidade do homem e demanda carinho e dedicação. O trabalho do auxiliar e do técnico de enfermagem vai para além dos cuidados de higiene e conforto, da medicação e do exame. $\mathrm{O}$ trabalho pede e necessita dos sentimentos que esses profissionais tenham para oferecer àqueles que estão sendo cuidados. Para Marta:

\section{A parte humana é o cuidado humanizado, tu cuidar do paciente que tá sentido dor e não pode deixar ele no desamparo, tu tem que ter um lado profissio- nal presente, porque a pessoa precisa da tua res- ponsabilidade, fazer com dedicação. Mas tu tem que ter o lado humano. Às vezes, tu quer dar uma palavra, nem que seja rápida, uma palavra de con- forto para aliviar.}

O trabalho do auxiliar e do técnico de enfermagem demanda sensibilidade destes profissionais e percepção das necessidades do paciente. Essa percepção vai além do prescrito pelo médico no prontuário como tratamento. Estas características tornam esse trabalho complexo, pois exige do trabalhador o investimento de sentimentos que precisam ser oferecidos a um estranho, o paciente.

Cuidador e cuidado não se conhecem e ao mesmo tempo tornam-se íntimos num curto espaço de tempo, pois o paciente chora, lastima, reclama, elogia, conta sua tragédia, conta suas alegrias, suas dores, seus remorsos e suas esperanças.

O cuidador que acompanha esse processo oferece apoio para o paciente que chora, lhe diz palavras de consolo e de esperança. E não está escrito que ele precise fazer isso. Isso não aparece no prescrito do trabalho. Como afirma Laura: "Tu cresce trabalhando na enfermagem. Crescimento é convívio, conhecimento, é saber o que o outro sente, tu compartilha com ele o que ele está sentindo, um sentimento, uma troca, isso te faz crescer".

Assim, o auxiliar e o técnico de enfermagem convivem diariamente com o desamparo, com a desesperança, com a angústia que assola aquele que adoece. Tem a missão de acompanhar, cuidar e oferecer recursos que possam auxiliar o paciente a superar seus sofrimentos.

Esse trabalho mostra-se singular, único, pois demanda desse profissional investimento afetivo, e isto não está prescrito. Entendendo o prescrito do trabalho, o que é determinado, ou seja, o que é pré-escrito a fim de ser executado pelos trabalhadores (Oliveira, 2002), o que não está descrito na lei, nem tampouco no Regulamento Interno da Enfermagem. Essa dedicação e investimento estão por conta do profissional, da sua criatividade, da 
sua invenção, percebendo-se aí um espaço para criação, conforme previsto por Dejours e Abdoucheli (1994), como necessário para o profissional se sentir realizado com a tarefa, potencializando este sujeito.

Esse espaço permite ao profissional inventar-se e reinventar-se como sujeito, de superação de si mesmo, permitindo, assim, sentir-se construtor de seu próprio trabalho, um espaço de invenção que pode oportunizarlhe realização pessoal. Isso torna o trabalho um desafio a ser desbravado, a ser descoberto, a ser solucionado, levando o trabalhador ao exercício de si mesmo, possibilitando sua própria transformação. Para Alexandre: “É uma satisfação pessoal, por eu tá trabalhando em uma coisa que eu gosto, que eu escolhi. Só o fato de eu tá trabalhando e gostar tanto da profissão já me satisfaz. Eu me sinto realizado".

Dejours (2001) diz que é essencial para transformar o trabalho fatigante em um trabalho equilibrante a necessidade de flexibilizar a organização do trabalho, de modo a deixar maior liberdade ao trabalhador para rearranjar seu modo operatório e para encontrar gestos que são capazes de lhe fornecer prazer, isto é, uma expansão ou uma diminuição de sua carga psíquica de trabalho.

Portanto, como o trabalho do auxiliar e do técnico de enfermagem possibilita criação, talvez se possa afirmar que este espaço entre o prescrito e o que de real o trabalho oferece possibilita a esse profissional um lugar de invenção, de criação, de investimento de si mesmo. Esta ligação afetiva que é estabelecida com o paciente e que contribui para a melhora deste é, sem dúvida, única e singular, pertencendo a cada profissional.É exclusiva com cada paciente, a cada instante, a cada momento. Um momento ímpar, o encontro do cuidador e de quem é cuidado no ambiente hospitalar.

\section{O cuidador e sua valorização profissional}

Além da satisfação encontrada no trabalho, para que este possa ser fonte de prazer, o reconhecimento do que fazem os auxiliares e técnicos de enfermagem é imprescindível, pois a valorização profissional também é vivida como prazerosa. Para tanto, é necessário o reconhecimento das ações do trabalhador, porque o trabalho envolve a expressão do sujeito, e ele encontra prazer e satisfação com sua obra, salientando assim suas potencialidades enquanto ser humano.

O reconhecimento do trabalho possibilita a transformação do sofrimento em prazer, pois dá sentido ao sofrimento, e ainda pode conduzir o sujeito para a construção de sua identidade, contribuindo assim para a sua auto-realização. Mostra-se um processo de construção de um sentido do trabalho na vida mental do trabalhador. Sem esse sentido é impossível a mobilização conjunta de sentimentos e inteligência para a criatividade. Dessa for- ma, quando a qualidade do trabalho desenvolvido pelos sujeitos é reconhecida, os seus esforços, suas angústias, suas decepções e seus desânimos adquirem sentido, contribuindo para que o sofrimento tenha um papel importante na transformação e na evolução do sujeito, (Dejours, 2001).

Esse prazer, essa satisfação dos auxiliares e técnicos de enfermagem, e conseqüentemente o reconhecimento de seus feitos, estão intimamente relacionados às características do trabalho que desempenham. Para Vanessa: "Prá mim é super satisfatório. Eu gosto de ver eles saindo bem. Te agradecem, pedem pra te ligar. Eles tentam criar um vínculo contigo. Eu gosto dessa parte, pra mim é o que gratifica".

Pitta (1994) também aponta que o reconhecimento social acerca do trabalho realizado pelos auxiliares e técnicos de enfermagem leva à obtenção de prazer na atividade profissional. Beck (2001) salienta que o reconhecimento e a gratificação do trabalho realizado pelos auxiliares e técnicos de enfermagem podem possibilitar um sentimento de pertencimento devido à aprovação e à aceitação da sociedade daquilo que eles fazem. Este sentimento manifesta-se quando eles conseguem alcançar as possibilidades oferecidas pelo trabalho.

Além desse sentimento de pertencimento, observa-se um sentimento de ser útil, e esta utilidade é que pode dar sentido ao trabalho que se faz, permitindo suportar a dor e o sofrimento do paciente. Como afirma Beatriz: "Trabalhando tu sabe que tu tá sendo útil. Tu te sente útil, ficando ao lado da pessoa. Cuidando dela, vendo o que ela precisa. A gente faz o que tá ao nosso alcance".

Dejours e Abdoucheli (1994) afirmam que o trabalho permite a diminuição da carga psíquica tornando-se fonte de equilíbrio, porém, quando se opõe à livre atividade para o aparelho psíquico, pode tornar-se perigoso. Contudo, o bem-estar relacionado à carga psíquica advém da descarga de energia psíquica que a tarefa permite, correspondendo a uma diminuição desta carga.

Possivelmente os sentimentos de pertencimento e de utilidade expressos pelos auxiliares e técnicos de enfermagem conduzem a uma diminuição da carga psíquica, tornando o trabalho equilibrante para o aparelho psíquico desses profissionais, evitando, assim, o desequilíbrio e a doença.

\section{Cuidar da Dor}

Os auxiliares e técnicos de enfermagem convivem com inúmeras adversidades: a dor, o sofrimento e a constatação da finitude humana, percebidas pela doença e pela morte. Os cuidadores que participaram desta pesquisa ainda enfrentam outras adversidades, como a de trabalhar em uma unidade crítica, o que exige desses 
profissionais ação rápida e eficaz, competência e segurança, devido ao risco iminente de morte em que se encontra o paciente da Emergência e da Unidade Pós-Operatória, não há espaço para dúvidas e insegurança.

Além disso, convivem com a imprevisibilidade, a complexidade e o processo de morte, que podem ser vivenciados com sofrimento por parte do trabalhador, pois este necessita experimentar diariamente angústias, medo, desesperança, desamparo e perda.

Dessa forma, nem só prazeres, realizações e reconhecimento profissional fazem parte do trabalho dos auxiliares e técnicos de enfermagem. Eles também sofrem. Muitas vezes, sofrem junto com o paciente. Para Vanessa: "Às vezes dá vontade de chorar, mas a gente tem que pensar, eu tô aqui para ajudar e não posso ficar assim. Tem coisas que são mais difíceis, mas a gente tem que continuar trabalhando".

Sabendo que o ato de cuidar exige do cuidador investimento afetivo, parece ser natural o fato de ele sofrer com a dor do paciente ou com a morte de alguém. Ver alguém morrer pode remeter a pensar em sua própria morte. Ou, ainda, negar o fato e ignorar a situação. Porém mesmo ignorando, esta morte já o afetou, nem que seja pelo fato de não querer pensar nela. E esse não pensar demanda esforço psíquico, pois o trabalhador precisa encontrar um pensamento de imediato para distrair, a fim de não pensar naquele indivíduo que morreu.

Parece compreensível que o auxiliar e o técnico de enfermagem também sofram. O importante é tornar esse sofrimento significativo o suficiente para que ele possa fazer sentido e não provocar um desequilíbrio psíquico no profissional, levando-o à doença.

Contudo, esconder esses sentimentos não parece ser o melhor caminho para significar e compreender tais sentimentos a ponto de não se tornarem perigosos para a saúde psíquica desses profissionais. No entanto, parece que esse é o caminho que muitos profissionais seguem, esconder ou fingir que eles não existem. $\mathrm{O}$ que pode se tornar perigoso, podendo ocasionar acúmulo de tensão não permitindo a descarga de energia psíquica, o que para Dejours e Abdoucheli (1994) pode ser perigoso, podendo ocasionar o desequilíbrio psíquico do trabalhador, pois o lugar que é marcado para gerar prazer, acaba gerando apenas sofrimento.

E este sofrimento é sem sentido, pois ele só ganha sentido, e conseqüentemente pode reverter-se em prazer, quando o trabalhador investe esforços para lutar contra ele, ocasionando o enfrentamento das dificuldades e das adversidades. O que, por sua vez, acionaria a criatividade, que é responsável pelo sentido do trabalho e conseqüentemente prazer, oferecendo reconhecimento do esforço e do sofrimento.

Contudo, esconder a própria dor não remete a esse caminho equilibrante apontado por Dejours e Abdoucheli
(1994), mas demonstra o uso de defesas individuais, que servem para amenizar a percepção da realidade, amenizando muitas vezes o sofrimento. Mas não apaga o sofrimento, esse continua existindo. Encontra-se, porém, escondido, disfarçado.

Parece que o cuidador está carecendo de um espaço onde ele possa falar da sua dor, compartilhar com os demais colegas o seu sofrimento e perceber que ele não é o único que também sofre com o trabalho que exerce. Um espaço onde ele possa dar sentido a esse sofrimento e, o mais importante, aceitá-lo, assumir que ele existe, entendê-lo e aprender a conviver com ele sem lhe causar desequilíbrios ou adoecimentos futuros. Poder proporcionar esse espaço pode contribuir para esse profissional compreender o que se passa com ele e, assim, prevenir o seu adoecimento.

\section{A dor do cuidador}

Uma das fontes de sofrimento do auxiliar e do técnico de enfermagem é a morte. Este sofrimento está vinculado à maneira como atualmente os homens a percebem. Pitta (1994) lembra que, na Idade Média, a morte era entendida como algo natural. Hoje ela se esconde nos hospitais, nas unidades críticas e nas emergências. Escondendo-a, buscando afastá-la do convívio social, caracterizando-a como incômoda, o homem nega aquilo que é inevitável na vida de todo ser vivo: a morte, dissociando, assim, a trajetória natural da vida, que é viver, adoecer e morrer. A vida não é percebida como limitada. "É frustrante quando o paciente vai a óbito" (Marina).

Como a vida não é percebida como limitada, observa-se a negação dessa realidade, e a negação é um mecanismo de defesa do ego. A função primordial do mecanismo de defesa é ajudar o indivíduo a fugir da ansiedade, da culpa, da dúvida e da incerteza, conforme aponta Pitta (1994). Negando a realidade, o trabalhador não possibilita a oportunidade de compreendê-la e até mesmo aliviar da angústia dos eventos que a proporcionam.

Negando essa realidade, não oportuniza a compreensão desses sentimentos, nem a sua livre expressão, o que vai interferir na descarga psíquica, e levar a uma maior tensão o aparelho psíquico, o que, consequientemente, pode possibilitar o seu adoecimento, pois a energia pulsional não está sendo descarregada no exercício do trabalho, ficando acumulada, gerando um sentimento de desprazer e tensão. A evolução desse processo pode ocasionar distúrbios de ordem física e psíquica no trabalhador, segundo Dejours (1992). Para Sandro: "Geralmente os técnicos sofrem da coluna. Aqui a gente pega bastante peso, tem pacientes mais gordos e pacientes que já estão crônicos são mais pesados ainda, pra trocar, dá banho, isso aí prejudica a coluna". 
Num levantamento realizado junto ao setor de Medicina do Trabalho do hospital estudado, constatou-se que no ano de 2005 uma média mensal de $11 \%$ de funcionários manteve-se afastada do trabalho para tratamento de saúde. Esse afastamento caracterizou-se em encaminhamento ao INSS (Instituto Nacional do Seguro Social). Deste índice, 52\% são auxiliares e técnicos de enfermagem.

Esses dados, em conjunto com os depoimentos desta pesquisa, justificam a necessidade de preocupar-se com a saúde desses profissionais, pois revelam que eles estão adoecendo.

Dejours (2001) fala da condição da banalização do sofrimento, em que o trabalhador desenvolve um amortecimento do corpo e do espírito como forma de sobreviver. Ao banalizar esse sofrimento todo, é como se o trabalhador não percebesse o seu real significado. É como se seu corpo estivesse anestesiado para a dor provocada pela necessidade de fazer força ao movimentar o paciente, de ficar em pé horas sem fim, de carregar maca, cadeira de rodas, etc., mas o sofrimento continua existindo.

Com essa atitude, o auxiliar e o técnico de enfermagem impedem a sua própria visão do evento, e a banalização passa a ser uma estratégia de esquecimento, pois admitir o sofrimento pode implicar reconhecer os seus próprios limites e, conseqüentemente, sentir-se impotente diante desses eventos.

Banalizar o sofrimento pode tornar-se uma tentativa de amenizá-lo. Esse recurso pode auxiliar o cuidador a continuar o seu trabalho, contudo pode acarretar um desfecho ainda pior, $\mathrm{o}$ adoecimento do próprio trabalhador.

$\mathrm{O}$ trabalhador pode vir a adoecer porque o sofrimento, mesmo sendo banalizado, não deixa de existir. Ele permanece, a angústia não ganha acomodação e os auxiliares e técnicos de enfermagem vão continuar se deparando com novos sofrimentos.

Este conformismo e esta aceitação do adoecimento do próprio corpo e o sentimento de que nada pode ser feito para mudar, revelam uma certa alienação. A busca do conhecimentoé uma ferramenta eficaz que pode intervir nesse processo, possibilitando um início de desalienação. Essas observações apontam para a necessidade da criação de um espaço de discussão e de compartilhamento para esses profissionais, a fim de que possam se tornar sujeitos ativos na busca de melhores condições de trabalho, na busca da sua própria saúde e na busca de um espaço de compreensão e alívio para o sofrimento.

\section{O descuido com o cuidador}

O trabalho do cuidador vem modificando-se ao longo do tempo. Antes sua tarefa era medicar o paciente conforme a prescrição médica, alimentá-lo, cuidar de sua higiene e conforto, ministrando os cuidados necessários, conforme a técnica aprendida. Atualmente, o auxiliar e o técnico de enfermagem necessitam preocupar-se também com outras questões: o controle de estoque, a burocracia, débitos e registros, como ocorre nos hospital estudado nesta pesquisa.

Os novos procedimentos de controle de estoque, a papelada que envolve a burocracia e os cuidados necessários com os débitos e registros na conta hospitalar do paciente têm a sua justificativa de existir e têm como objetivo otimizar o resultado financeiro das instituições de saúde, tendo em vista que essas medidas são exigidas pelos convênios de saúde e SUS (Sistema Único de Saúde). Contudo, este acréscimo de responsabilidades para esse profissional representa atraso no atendimento ao paciente, gerando ainda mais tensão no seu cotidiano de trabalho.

Além do fato dessas rotinas serem herdeiras do taylorismo: quem as define e as planeja está distante daqueles que as executam. Isso facilita a inadequação das rotinas com relação à real necessidade enfrentada no cotidiano de trabalho.

O cuidador está preocupado com o imediatismo da ação necessária ao atendimento do paciente, enquanto os registros atrasam esse imediatismo. Tais registros são necessários, contudo os depoimentos mostram as dificuldades enfrentadas pelos auxiliares e técnicos de enfermagem que buscam atender o paciente. Constata-se, assim, a necessidade de buscar espaços de discussão entre a equipe, a fim de encontrarem soluções que atendam às necessidades do trabalhador, do paciente e da área financeira. Para Laura: "O difícil é não ter material para trabalhar. Às vezes falta as coisas, tu tem que ficar improvisando. Falta funcionário, fica com excesso de paciente, tu não consegue dar atenção necessária, isso é que dificulta".

Esse depoimento reflete a realidade do Sistema de Saúde no Brasil: falta de material para trabalhar, número inadequado de trabalhadores para atender à demanda e o excesso de pacientes em relação à capacidade de atendimento dos Serviços de Saúde.

Trata-se aqui de um problema que não é exclusivo deste hospital e reflete as dificuldades pelas quais passam a maior parte das instituições que atendem o Sistema Único de Saúde no Brasil. Contudo, esses cuidadores acabam assumindo para si a responsabilidade das conseqüências desses problemas, gerando-lhes angústia e sobrecarga de tensão.

Para Beck (2001), a possibilidade que o cuidador tem de promover o alívio do sofrimento do outro pode significar a reposição de energia, a busca do equilíbrio e bem-estar. O que, diante desse cenário descrito pelos depoimentos anteriores, não está acontecendo, podendo esses aspectos também contribuírem para o adoecimento do trabalhador, pois esses eventos causam apenas tensão. 
Como são problemas relacionados a uma realidade nacional, que envolve investimento financeiro e mudanças nas políticas públicas, entende-se que seja um problema cuja solução não será imediata, portanto esses trabalhadores continuarão a enfrentar essa realidade diariamente em seu trabalho.

Outro advento que traz dificuldades para alguns é o trabalho noturno. Conforme Marta:

No começo eu sentia uma náusea durante o dia, muda tudo, é outra rotina né. Dia sim, dia não tu dorme de dia outro dia de noite. Mas depois ficou normal. E também no começo eu dormia quase o dia todo, agora não, durmo 3 ou 4 horas e já ta bom.

Fica evidente no relato acima a estranheza para o ritmo biológico do trabalho noturno. Contudo, nenhum dos pesquisados informou que gostaria de trocar de horário, provavelmente porque trabalhar no turno da noite represente uma forma de um incremento na remuneração, pelo fato de se ganhar adicional noturno. Novamente, evidencia-se a banalização do sofrimento, pois o corpo sofre com o ritmo estranho ao natural, na medida em que a noite foi feita para dormir e não para trabalhar. $\mathrm{E}$ atualmente existe uma lista de espera de funcionários do diurno que estão aguardando uma oportunidade para trocarem de turno, desejando ir para a noite.

Acredita-se que isso possa estar relacionado com outra adversidade que enfrenta o cuidador e que lhe atinge de forma direta na sua vida privada, a sua remuneração, pois os cuidadores vendem a sua força de trabalho para administrar os incômodos da doença e do morrer, são os guardiões, e, segundo Pitta (1994), nem sempre são esclarecidos de sua penosa missão. E a remuneração que recebem por estarem cuidando do trágico é na maioria das vezes pouca, proporcionando um precário poder aquisitivo, refletindo direto na sua qualidade de vida.

Conviver com essa realidade faz parte da vida do cuidador. E como é possível trabalhar com dedicação, se a instituição não está cuidando desses profissionais adequadamente? A instituição necessita cuidar do cuidador para ele continuar cuidando do paciente.

\section{Considerações Finais}

Algumas pessoas escolheram como profissão o cuidar. Cuidar de quem se encontra fragilizado, enfermo, moribundo, sofrendo, desesperado, cuidar daquele que está doente e pode ficar curado ou daquele que pode morrer. $\mathrm{O}$ cuidador acompanha a trajetória dos pacientes enquanto estes se encontram internados. E esse acompanhamento pode lhe proporcionar prazeres e sofrimentos.

Ele encontra prazer no que faz porque o seu trabalho proporciona um espaço de criação, onde ele pode inventar-se e reinventar-se como sujeito, pode construir sua identidade, pode realizar e contemplar sua própria obra. Tudo isso porque existe um espaço entre o trabalho prescrito e o trabalho real que permite ao cuidador construir a relação que estabelece com o paciente, e esta é única, pertence a cada trabalhador.

Além de encontrar através de seus pares e dos próprios pacientes o reconhecimento de seu trabalho, este é propiciador de sentido ao que ele faz, possibilitando aos auxiliares e técnicos de enfermagem gostarem daquilo que fazem e serem felizes com a sua profissão, transformando assim o sofrimento em prazer.

Contudo, nem só de amores eles vivem. Existe o sofrimento que acompanha a tarefa de presenciar a dor e o sofrimento do paciente. Esse trabalho oferece também sofrimento ao trabalhador, pois ele procura esconder a sua própria dor gerada por acompanhar o doente e isso pode proporcionar acúmulo de tensão podendo levar, com o tempo, o cuidador ao adoecimento.

Criar um espaço onde ele possa compartilhar e compreender esse sofrimento e ainda significar esses eventos para que possa continuar com saúde faz-se necessário e urgente.

Foi constatado o número significativo de profissionais da enfermagem que se encontram afastados em licença saúde, sinalizando que o trabalho pode estar causando problemas de saúde e que estes necessitam ser prevenidos, a fim de evitar mais sofrimento a esses trabalhadores.

Refletir e discutir sobre as vicissitudes do trabalho, os eventos geradores de prazer e de sofrimento parece ser uma medida necessária para esses trabalhadores encontrarem meios de continuar trabalhando de forma saudável, bem como este hospital preocupar-se e agir a favor da saúde desses profissionais.

\section{Referências Bibliográficas}

Bardin, L. (1977). Análise de conteúdo. Lisboa: Edições 70.

Beck, C. L. C. (2001). O sofrimento do trabalhador: da banalização a re-significação ética na organização da enfermagem. Florianópolis: UFSC.

Brasil. (1986). Lei 7.498, de 25 de junho de 1986. Dispõe sobre a regulamentação do exercício da enfermagem e dá outras providências. Acesso em 14 de dezembro, 2008, em http:// www.portalcoren-rs.gov.br/web/legislação/leis/17498.htm

Codo, W., Sampaio, J. J. C., \& Hitomi, A. H. (Orgs.). (1994). Indivíduo, trabalho e sofrimento: uma abordagem interdisciplinar. Rio de Janeiro: Vozes.

Dejours, C. (1992). A loucura do trabalho - estudo de psicopatologia do trabalho ( $5^{\mathrm{a}}$ ed.). São Paulo: Cortez.

Dejours, C. (1994). Trabalho e saúde mental: da pesquisa à ação. In M. I. S. Betiol (Coord.), Psicodinâmica do trabalho - Contribuições da Escola Dejouriana à análise da relação prazer, sofrimento e trabalho (pp. 45-65). São Paulo: Atlas.

Dejours, C. (1997). O fator humano. Rio de Janeiro: Fundação Getúlio Vargas. 
Dejours, C. (1999). Conferências brasileiras - Identidade, reconhecimento e transgressão no trabalho. São Paulo: Fundap.

Dejours, C. (2001). A banalização da injustiça social (4a ed.). Rio de Janeiro: Fundação Getúlio Vargas.

Dejours, C. (2004). Addendum - A metodologia em psicopatologia do trabalho. In S. Lancman \& L. I. Sznelwar (orgs.), Christophe Dejours: da psicopatologia à psicodinâmica do trabalho. Rio de Janeiro: Fiocruz.

Dejours, C. \& Abdoucheli, E. (1994). Itinerário teórico em psicopatologia do trabalho. In M. I. S. Betiol (Coord.), Psicodinâmica do trabalho - Contribuições da Escola Dejouriana à análise da relação prazer, sofrimento e trabalho (pp. 119-145). São Paulo: Atlas.

Lancman, S. \& Sznelwar, L. I. (Orgs.). (2004). Christophe Dejours: da psicopatologia à psicodinâmica do trabalho. Rio de Janeiro: Fiocruz.

Heller, A. (1991). Sociologia de la vida cotidiana. Barcelona: Península.

Merlo, A. R. C. (1999). A informática no Brasil-Prazer e sofrimento no trabalho. Porto Alegre: Ed. da Universidade/UFRGS.

Oliveira, P. A. B. (2002). Trabalho prescrito e trabalho real. In A. D. Cattani (Org.), Dicionário crítico sobre trabalho e tecnologia (4ª ed., pp. 350-353). São Paulo: Vozes.

Osório, L. C. (2003). Psicologia grupal: uma nova disciplina para o advento de uma era. Porto Alegre: Artmed.

Pitta, A. (1994). Hospital dor e morte como ofício (3a ed.). São Paulo: HUCITEC.

Sampaio, J. J. C., Hitomi, A., \& Ruiz, E. M. (1995). Saúde e trabalho: uma abordagem do processo e jornada de trabalho. In W. Codo \& J. J. C. Sampaio (Orgs.), Sofrimento psíquico nas organizações: saúde mental e trabalho (pp. 65-84). Petrópolis, RJ: Vozes.

Silva, C. O. (1998). Trabalho e Subjetividade no Hospital Geral. Psicologia Ciência e Profissão, 18(2), 26-33.

Tittoni, J. (2002). Saúde Mental. In A. D. Cattani (Org.), Dicionário crítico sobre trabalho e tecnologia ( $4^{\mathrm{a}}$ ed., pp. 279-283). São Paulo: Vozes.

Vaz, M. R. C. (1995, abril/junho). Reflexões concernentes ao conceito de trabalho e a cotidianidade. Revista Brasileira de Enfermagem, Brasília, 48(2), 168-171.

Aline Gonçalves Machado é Psicóloga do Instituto de Cardiologia do Rio Grande do Sul, Especialista em Saúde e Trabalho pela UFRGS e Mestre em Psicologia Social e Institucional pela UFRGS.Endereço para correspondência: Av. Princesa Isabel, 395. Santana. Porto Alegre, RS, Brasil. CEP 90620-001 Email: aline machado@ibest.com.br

Álvaro Roberto Crespo Merlo é Médico do Trabalho, Doutor em Sociologia pela Universidade Paris 7 - Denis

Diderot, Docente da Faculdade de Medicina e dos Programas de Pós-Graduação em Psicologia Social e Institucional e em Epidemiologia da UFRGS e Professor Médico-Assistente do Hospital de Clínicas de Porto

Alegre. Endereço para correspondência: Rua Tomaz Flores, 122/501. Porto Alegre, RS, Brasil. CEP 90035-200 E-mail: merlo@ufrgs.br

\section{Cuidadores: seus amores e suas dores}

Aline Gonçalves Machado e Álvaro Roberto Crespo Merlo

Recebido: 08/05/2007

Revisão: 05/06/2008

Aceite final: 13/06/2008 